\title{
A CRITICAL REVIEW ON HYPOTHESIS, PATHOPHYSIOLOGY OF SCHIZOPHRENIA, AND ROLE OF VITAMINS IN ITS MANAGEMENT
}

\author{
ROSMI JOSE ${ }^{1}$, VENKETESWARAMURTHY ${ }^{2 *}$, SAMBATH KUMAR R ${ }^{3}$ \\ ${ }^{1}$ Department of Pharmacy Practice, J.K.K. Nattraja College of Pharmacy, Komarapalayam - 638 183, Tamil Nadu, India. ${ }^{2}$ Department of \\ Pharmacy Practice, J.K.K. Nattraja College of Pharmacy, Komarapalayam - 638 183, Tamil Nadu, India. ${ }^{3}$ Department of Pharmaceutics, \\ J.K.K. Nattraja College of Pharmacy, Komarapalayam - 638 183, Tamil Nadu, India. Email: venkateswaramurthy.n@jjkn.org
}

Received: 04 December 2017, Revised and Accepted: 25 April 2018

ABSTRACT

This review describes about the literatures addressing the role of vitamin supplementation in schizophrenia. Evidence is suggesting that vitamin supplementation includes Vitamin A, Vitamin D, Vitamin E, Vitamin B complex, and Vitamin C may be important in treatment. In schizophrenia, patients may have increased level of homocysteine (Hcy), due to the polymorphism in methylenetetrahydrofolate reductase and hypofunction of $\mathrm{N}$-methyl-D-aspartate receptors. The vitamins main effects are reduced the Hcy level and maintain dopamine and serotonin levels. Add-on treatment with high-dose B vitamins including B6, B9, and B12 and also Vitamin D can significantly reduce symptoms of schizophrenia more than standard treatments alone.

Keywords: Schizophrenia, Vitamin B, Vitamin D.

(c) 2018 The Authors. Published by Innovare Academic Sciences Pvt Ltd. This is an open access article under the CC BY license (http://creativecommons. org/licenses/by/4. 0/) DOI: http://dx.doi.org/10.22159/ajpcr.2018.v11i8.23259

\section{INTRODUCTION}

Schizophrenia is a psychiatric illness, which occurs by disruptions in their thinking, perception, affecting language and also self-sense. It involves psychotic experiences such as auditory hallucinations and delusions and also impairs functioning like daily activities [1]. It causes alterations in the distressed person's thinking, functioning, perception, and behavior [2]. It mostly affects males (early twenties) than females (early thirties) [3]. The interactions among genes, environmental and psychosocial factors are also the factors for schizophrenia [4]. Schizophrenia patients have high level of homocysteine (Hcy) in plasma or even methylenetetrahydrofolate reductase (MTHFR) polymorphisms. Hcy of high level in plasma may lead to neurotoxicity through the Hcy effect on N-methyl-D-aspartate receptors (NMDARs) [5].

In psychiatric disorders, the schizophrenia not a common one and 21 million of peoples were affected worldwide. The mortality rate of patients, with schizophrenic, is 2-2.5 times more than normal population. The symptoms reduced by proper treatment but not cured completely. The therapy goal is to improve the life quality and restore psychosocial functioning [4].

\section{Hypothesis and pathophysiology of schizophrenia}

Protein misfolding and their accumulation inside or outside the neurons are the major pathological features in the neurodegenerative diseases [6]. Several hypotheses are available for schizophrenia, which includes genetical, neurodevelopmental, glutamatergic, neurochemical (dopamine), and GABAergic hypothesis.

Genetical hypothesis postulates the development of schizophrenia may due to that specific cluster of genes will undergo addition or potentiation determines the individual genetic vulnerability $[7,8]$. The genetic polymorphism results in gene expression or function alteration, in which the genetic variants like single-nucleotide polymorphisms have minor impact [9].

Neurodevelopmental hypothesis, the effects during the development of embryonal, and fetal brain can result alteration in biochemical functioning and defect in neural connectivity, which resulting in emotional, cognitive, and intentional dysfunction $[10,11]$.

Glutamatergic dysfunction, a hypofunction of glutamate in corticostriatal projections results a sensory flooding and psychotic symptoms and changes in dopamine concentration occurs by an opening effect in the thalamocortical loop. The glutamate receptors are of two groups, ionotropic ligand-gated ion channels and metabotropic $\mathrm{G}$ protein-coupled receptors [12]. The ionotropic glutamate receptors act as ion channels which bind to glutamate and generating a depolarizing excitatory post-synaptic current. NMDARs are allosteric tetrameric and ligand-gated calcium channels, moderated by ions, and endogenous ligands. It is involved in the signal transduction, which is memory related by magnesium that can induce voltage-dependent block. NMDARs are supposed to cause neuroinflammation and apoptosis by excitotoxicity and subsequent downstream events [13].

$\mathrm{N}$-Acetyl cysteine (NAC), precursor to glutathione (GSH), is deficient in the schizophrenic patients[14] and increases plasma GSH levels [15]. It releases cysteine, which may influences/modulates the glutamatergic system by act as substrate and leads to the decrease in symptoms [16]. A clinical trial conducted in schizophrenic patients shows that the administration of $1000 \mathrm{mg} \mathrm{NAC}$ twice daily over 24 weeks along with antipsychotic drugs, has a decrease in negative symptoms, global function, and akathisia [17]

Dopamine hypothesis explains that dopaminergic neurotransmission, especially in brain regions, mesolimbic, and striatal regions, leads to positive symptoms and dopaminergic deficits in prefrontal regions, which are accountable for the negative symptoms. The dopamine D2 receptor density is higher in caudate was linked with poorer response on cognitive functions involving corticostriatal pathways, a genetic risk for schizophrenia [18].

In GABAergic hypothesis, the 67 and $65 \mathrm{kDa}$ isoforms of glutamic acid decarboxylase (GAD) are the key enzymes for the GABA synthesis, which is present in altered levels in postmortem brain of patients with schizophrenia. A decline in GAD67 transcript levels has been found in prefrontal and temporal cortex [19]. Certain studies showed that 
schizophrenic patients have greater MTHFR mutations which may lead to higher level of plasma Hcy concentration, which has proposed to be risk factor in the development of schizophrenia [7].

The medicinal plants, rich sources of phytochemicals and other active constituents and vitamins, have a major role in neuroprotection [20].

\section{VITAMINS AND SCHIZOPHRENIA}

Vitamin deficiencies which may lead to the development of schizophrenia are as follows:

- Vitamin A

- Vitamin D

- Vitamin E

- Vitamin B complex

- Vitamin C.

\section{VITAMIN A (RETINOID)}

Vitamin A known as retinoid cannot be synthesized in the body and generally has role in the gene expression, proliferation, cell differentiation, migration, and death. The Vitamin A derivative, retinoic acid (RA) is a potent teratogenic agent and its deficiency may lead to the occurrence of certain diseases such as schizophrenia, psychosis, abnormalities in craniofacial, limb, digit, heart, and urogenital, and these are changes that will occur in schizophrenia. Hence, Vitamin A is essential in the early stage of embryo development and throughout fetal development, but its role is less known in adult brain [21]. Hydrocephalus, characterized by increased the third or fourth ventricle size and/or decreased in the size [22-24] of the hind or forebrain, is a characteristic pattern of retinoid toxicity. The nuclear receptors for RA and the transport proteins for retinoid metabolites are present in all parts of the brain, and delivery of retinoid is controlled throughout embryonic, fetal, and postnatal development [21].

The schizophrenic phenotype and the disease gene phenotype may arise from disruption of the disease gene function by one of the several mutations. Retinoid are profoundly altered the lysosomal enzymes ${ }^{[25,26]}$ release and had a role in the regulation of the glucocerebrosidase gene. Retinoid dysregulation of the non-mutated gene might result in an end phenotype, psychosis that resembles the psychosis which caused by mutant gene, but without the requirement of gene mutation. Alteration of neurotransmitters is a classic hallmark of the psychosis, and treatments in schizophrenia reflect neurotransmitters action in the psychotic process [27].

Bao et al. [28], conducted a population-based study and found that low Vitamin A level in the second trimester associated with increase in disease by 3-fold and no association during the third trimester. Hence, Vitamin A supplementation is more important in pregnant women to avoid the fetal abnormalities.

\section{VITAMIN D (CALCIFEROL)}

Vitamin D (calciferol) is both fat-soluble vitamin and steroid hormone. It is found in fish, eggs, vegetable oils, butter, liver, and in fortified milk $[29,30]$ and synthesized in the epidermis of the skin from 7-dehydrocholesterol, by the ultraviolet B component of sunlight [31] it converted to Vitamin D3 (cholecalciferol). Vitamin D receptors are also present in various zones in the central nervous system (CNS) of the human brain [32-35] and potent inducer for the synthesis of nerve growth factor. Vitamin D is neuroprotective [36], prodifferentiating and antiproliferative agent [37], which have role in many brain processes, and Vitamin D deficiency is manifested by rickets [31] and finally leads to osteomalacia, osteoporotic bone fractures, cancer, autoimmune, infectious, and cardiovascular diseases [38]. Perinatal Vitamin D deficiency is a risk factor for the schizophrenia $[39,40]$, especially in older peoples as they have thin or pigmented skin $[41,42]$. A meta-analysis shows that the schizophrenic patients may have lower level of Vitamin D than healthy peoples (mean difference $14.77 \mathrm{nmol} / \mathrm{l} ; 5.91 \mathrm{ng} \mathrm{mL}$ ) [43].
Jan et al. [44] found that in therapy-refractory patients should check Vitamin D level routinely. Adequate serum Vitamin D concentration is preventing new episodes or in helping in the treatment of psychotic symptoms [29]. Severe negative and cognitive deficits associated with Vitamin D deficiency [45].

\section{VITAMIN E (TOCOPHEROL)}

Tocopherol, an antioxidant which is lipid soluble, used in schizophrenic patients to mimics the antioxidant defense system deficits and oxidative damage [46]. Reduced GSH (reduced forms of GSH) level is found in red blood cells of patients [47] and oxidized (glutathione disulfide) forms of GSH level were reduced in patients who receive Vitamin E therapy [48]. GSH has vital role in cellular protection [49] and its concentration is reduced in cerebrospinal fluid (CSF), prefrontal cortex, and postmortem caudate of schizophrenic patients [16,50-54]. The adjunctive intake of Vitamins $\mathrm{C}$ and $\mathrm{E}$ in schizophrenia needs care because the high dietary intake will cause prooxidant rather than antioxidant actions [55].

Dorfman-Etrog et al. [56] conducted a study to observe the Vitamin E effect with supplemental therapy on acute extrapyramidal symptoms in patients, who undergone therapy with neuroleptic drugs, and they concluded that adjunctive therapy of Vitamin E and neuroleptics may diminish the acute neuroleptic severity, which is induced by parkinsonism (neuroleptic-induced parkinsonism) in schizophrenia patients.

\section{VITAMIN B COMPLEX}

Vitamin B complex, water-soluble supplements and they do not present in the body for long, and its major action in schizophrenia is the methyl group donation for the synthesis of proteins, nucleic acids, lipids, hormones, and neurotransmitters, especially Vitamin B9, B6, and B12 [57]. The blood levels with low content of Vitamin B are a relatively consistent finding in schizophrenia patients, but the exact relationship between $B$ vitamin status and risk of cognitive or behavioral disorders is unclear. Vitamin B complex will not interfere with antipsychotics, but on an empty stomach, it will cause nausea, stomach discomfort, and yellowing of the urine, not to worry about these effects [58].

\section{Vitamin B12 (cyanocobalamine)}

Among youngest peoples, Vitamin B12 level was 10 times more than elder peoples, which contributes protection of brain by slowing free radicals production and cellular reactions. Free radicles are the DNA damaging chemicals [59]. The Vitamin B12 level may decline with age, mainly the methylcobalamin in human frontal cortex, which has role in the regulation of methylation reactions and gene expression. Vitamin B12 deficiency causes accumulation of dopamine, which may cause the psychosis resistant to antipsychotic therapy, psychosis reversed by Vitamin B12 supplementation by not developing any extrapyramidal side effects. While analyzing the previous surveys, it was found that $6-15 \%$ psychiatric patients have low B12 level [60].

High Hcy level has involvement in neurological and psychological disorders like schizophrenia [61,62]. Hcy binds with NMDAR and alters glutamatergic transmission, results in dopaminergic neuron toxicity, which cause neuronal apoptosis and oxidative stress, leads to dysfunction in mitochondria, and affects DNA methylation altering gene expression [60].

The methyl group of methionine is activated by converting it to S-adenosyl methionine (SAM), sole methyl donor CNS by adenosine triphosphate, and ethionine adenosyltransferase. S-adenosyl Hcy, the demethylation product of SAM, is then hydrolyzed to Hcy in a reversible reaction. Vitamin B12-dependent enzyme, methionine synthase is involved in the remethylation of Hcy to methionine in tissues.

Many studies found that the main etiological factor for schizophrenia is deficiency of Vitamin B12 and higher homocysteinemia [61,63,64]. Not only Vitamin B12 deficiency but also Vitamins B6 and B9 can also cause 
schizophrenia, and the symptoms can reduce by supplementation of vitamins along with the antipsychotics $[65,66]$

\section{Vitamin B9 (folic acid/folate)}

Folic acid is present in leafy greens and meat, needed vitamin for neuron function. Some cases show that it is important for the dementia and schizophrenia patients for energy regulation [67]. The deficiency of folate alone or in combination with monoamine precursors such as Vitamins B6 and B12 may predispose to depression or aggravate mood disorders if already present [68]. Sensitive measures are total Hcy and Vitamin B12 levels for folate deficiency. There also has a link between folic acid deficiency and impaired metabolism of noradrenaline, dopamine, and serotonin [69].

A double-blind placebo-controlled study by Godfrey et al. concluded that the patients have Vitamin B9 deficiency and the symptoms improved by daily folate supplementation [70]. Increase in the low functioning of MTHFR load may be the risk for developing negative symptoms, and in genotype, there is no difference in folate levels [71]. Inverse relationship is present between severity of negative symptom and folate level [72].

\section{Vitamin B6 (pyridoxine)}

Pyridoxine is essential in the amino acids processing the building blocks of proteins, some hormones, dopamine, serotonin, and melatonin. Vitamin B6 is more effective in tardive dyskinesia to decrease the symptoms [73]. The $100 \mathrm{mg}$ /day is the tolerable limit for Vitamin B6, which is established by Institute of Medicine for adults. Pyridoxine-P and pyridoxal phosphate are the active cofactor form, which is formed by the phosphorylation of pyridoxine and an oxidized form of pyridoxal by the enzyme pyridoxal kinase in the liver. Pyridoxine, a coenzyme for the synthesis of dopamine, serotonin, GABA, carbohydrate and amino acid metabolism. Hence, B6 deficiency may lead to seizures and mental retardation [74].

Lerner et al. [75] conducted a study to examine the relationship between psychotic symptoms in both schizophrenic and schizoaffective patients (DSM-IV criteria) and Vitamin B6 therapy. The patients received Vitamin B6 supplementation, $100 \mathrm{mg} /$ day in the $1^{\text {st }}$ week and then $100 \mathrm{mg}$ increments each week up to $4^{\text {th }}$ week and measure the positive and negative syndrome scale (PANSS). The PANSS scores have shown that no variations in the mental state of patients between test and placebo. However, they also concluded that more population is necessary to determine the effect of Vitamin B6 in schizophrenia. A double-blind, randomized, placebo-controlled crossover study in 42 schizophrenia inpatients with plasma Hcy levels $>15 \mu \mathrm{mol} / \mathrm{L}$ and daily administration of folate $2 \mathrm{mg}$, pyridoxine $25 \mathrm{mg}$, and $400 \mu \mathrm{g}$ of Vitamin B12 for 3 months and also 3 months for placebo, they found that the lower level of Hcy causes the schizophrenia and vitamin supplementation can reduce the symptoms [76].

\section{VITAMIN C (ASCORBIC ACID)}

The role of ascorbic acid in schizophrenia, not exactly elucidated, and the content is highest in brain and CSF than in other body tissues [77]. Deficiency in ascorbic acid content will cause the increase in brain acetylcholinesterase activity, dopamine levels [78,79], and decrease level of norepinephrine level. Vitamin C has action in serotonin synthesis, by the conversion of tryptophan to 5-hydroxytryptophan and also in the binding of serotonin to its receptors [80]. Serotonin precursors are used in schizophrenia treatment had only a slight effect [81], and they require higher loading doses of ascorbic acid to excrete the substance in normal amounts through urine [82-84]. Ascorbate in high amounts may exert antipsychotic effects by inhibiting dopaminergic activity [85-87].

Vitamin C supplementation with antipsychotics reverses concentration of ascorbic acid, which causes reduction in the oxidative stress and thus increases brief psychiatric rating scale score, hence, in the schizophrenic treatment, both the drugs in combination can be used for the effectiveness [88].

\section{CONCLUSION}

Many studies reveal that hyperhomocysteinemia and vitamin deficiencies, especially Vitamin D, Vitamin B12, Vitamin B9, and Vitamin B6 may be the responsible factors for schizophrenia. Antipsychotic medications with high doses may only need for a brief period until patients attain mental stability after that low dose of antipsychotic medications with vitamin supplements will gradually help the patients to be back to normal or near-normal function. It is necessary to conduct more extensive studies to observe the schizophrenia incidence and its relation to genetic, prenatal, and malnutrition.

\section{AUTHOR'S CONTRIBUTION}

All authors had contributed equally to the review work.

\section{CONFLICTS OF INTEREST}

All authors have none to declare.

\section{REFERENCES}

1. Schizophrenia. World Health Organization (WHO). 2017. Available from: http://www.who.int/topics/schizophrenia/en.

2. Jonathan EP. The clinical use of orthomolecules in the treatment of schizophrenia: Critical reflections and commentary. J Orthomol Psychiatry 2014;29:141-53.

3. Schultz SH, North SW, Shields CG. Schizophrenia: A review. Am Fam Physician 2007;75:1821-29.

4. Sridhar S, Ravi K, Raju M, Thomas L. A pilot study on utilization pattern of antipsychotic drugs in schizophrenic patients from southern India. WJPPS 2017;6:1301-8.

5. El-Hadidy MA, Abdeen HM, Abd El-Aziz SM. MTHFR gene polymorphism and age of onset of schizophrenia and bipolar disorder. Biomed Res Int 2014;2014:1-9.

6. Roy S, Awasthi H. Herbal medicines as neuroprotective agent: A mechanistic approach. Int J Pharm Pharm Sci 2017;9:1-7.

7. Gottesman II, Shields J. A polygenic theory of schizophrenia. Proc Natl Acad Sci USA 1967;58:199-205.

8. Harrison PJ, Weinberger DR. Schizophrenia genes, gene expression, and neuropathology: On the matter of their convergence. Mol Psychiatry 2005; 10:40-68.

9. Lang UE, Puls I, Muller DJ, Strutz-Seebohm N, Gallinat J. Molecular mechanisms of schizophrenia. Cell Physiol Biochem 2007;20:687-702.

10. Raedler TJ, Knable MB, Weinberger DR. Schizophrenia as a developmental disorder of the cerebral cortex. Curr Opin Neurobiol 1998;8:157-61.

11. Harrison PJ. The neuropathology of schizophrenia. A critical review of the data and their interpretation. Brain 1999;122:593-624.

12. Steen RG, Mull C, McClure R, Hamer RM, Lieberman JA. Brain volume in first-episode schizophrenia: Systematic review and metaanalysis of magnetic resonance imaging studies. $\mathrm{Br} \mathrm{J}$ Psychiatry 2006;188:510-8.

13. Seeman P, Kapur S. Schizophrenia: More dopamine, more D2 receptors. Proc Natl Acad Sci USA 2000;97:7673-75.

14. Tuominen HJ, Tiihonen J, Wahlbeck K. Glutamatergic drugs for schizophrenia: A systematic review and meta-analysis. Schizophr Res 2005;72:225-34.

15. Sansone RA, Sansone LA. Getting a knack for NAC: N-acetyl-cysteine. Innov Clin Neurosci 2011;8:10-4.

16. Lavoie S, Murray MM, Deppen P, Knyazeva MG, Berk M, Boulat O, et al. Glutathione precursor, $\mathrm{N}$-acetyl-cysteine, improves mismatch negativity in schizophrenia patients. Neuropsychopharmacology 2008;33:2187-99.

17. Dean O, Giorlando F, Berk M. N-acetylcysteine in psychiatry: Current therapeutic evidence and potential mechanisms of action. J Psychiatry Neurosci 2011;36:78-86.

18. Berk M, Copolov D, Dean O, Lu K, Jeavons S, Schapkaitz I, et al. $\mathrm{N}$-acetyl cysteine as a glutathione precursor for schizophrenia--a double-blind, randomized, placebo-controlled trial. Biol Psychiatry 2008;64:361-8.

19. Akbarian S, Kim JJ, Potkin SG, Hagman JO, Tafazzoli A, Bunney WE Jr., et al. Gene expression for glutamic acid decarboxylase is reduced without loss of neurons in prefrontal cortex of schizophrenics. Arch Gen Psychiatry 1995;52:258-66. 
20. Phukan P, Bawari M, Sengupta M. Promising neuroprotective plants from north-east India. Int J Pharm Pharm Sci 2015;7:28-39.

21. Ann BG. Chromosomal locations and modes of action of genes of the retinoid (Vitamin A) system support their involvement in the etiology of schizophrenia. Am J Med Genet 1995;60:335-48.

22. Lammer E. Preliminary observations on isotretretinoin induced ear malformations and pattern formation of the external ear. J Craniofac Genet Dev Biol 1991;11:292-5.

23. Hoffman C, Eichele G. Retinoids in development. In: Sporn MB, Roberts AB, Goodman DS, editors. The Retinoids: Biology, Chemistry and Medicine. $2^{\text {nd }}$ ed. New York: Raven Press; 1994. p. 387441.

24. Morriss KG. Retinoic acid and craniofacial development. Bio Essays 1993;15:9-15

25. Dingle JT, Barrett AJ, Weston PD, Cathepsin D. Characteristics of immunoinhibition and the confirmation of a role in cartilage breakdown. Biochem J 1971;123:1-13.

26. Camisa C, Eisenstat B, Ragaz A, Weissmann G. The effects of retinoids on neutrophil functions in vitro. J Am Acad Dermatol 1982;6:620-9.

27. Meltzer HY. Treatment of the neuroloptic-nonresponsive schizophrenic patient. Schizophr Bull 1992;18:414-542.

28. Bao Y, Ibram G, Blaner WS, Quesenberry CP, Shend L, McKeagu LW, et al. Low maternal retinol as a risk factor for schizophrenia in adult offspring. Schizophr Res 2012;137:159-65.

29. McGrath J. Hypothesis: Is low prenatal vitamin D a risk-modifying factor for schizophrenia? Schizophr Res 1999;40:173-77.

30. McGrath J, Saari K, Hakko H, Jokelainen J, Jones P, Järvelin MR, et al. Vitamin D supplementation during the first year of life and risk of schizophrenia: A Finnish birth cohort study. Schizophr Res 2004;67:237-45

31. Stumpf WE, Sar M, Clark SA, DeLuca HF. Brain target sites for 1, 25-dihydroxyvitamin D3. Science 1982;215:1402-5.

32. Sutherland MK, Somerville MJ, Yoong LK, Bergeron C, Haussler MR, McLachlan DR. Reduction of vitamin D hormone receptor mRNA levels in Alzheimer as compared to Huntington hippocampus: Correlation with calbindin-28 k mRNA levels. Brain Res Mol Brain Res 1992;13:239-50.

33. Veenstra TD, Prufer K, Koenigsberger C, Brimijoin SW, Grande JP, Kumar R. 1,25-Dihydroxyvitamin D3 receptors in the central nervous system of the rat embryo. Brain Res 1998;804:193-205.

34. Prufer K, Veenstra TD, Jirikowski GF, Kumar R. Distribution of 1,25dihydroxyvitamin D3 receptor immune reactivity in the rat brain and spinal cord. J Chem Neuroanat 1999;16:135-45.

35. Musiol IM, Feldman D. 1,25-Dihydroxyvitamin D-3 expoinduction of nerve growth factor in L929 mouse fibroblasts: Effect of vitamin D receptor regulation and potency of vitamin D-3 analogs. Endocrinology 1997; 138:12-8.

36. Eyles D, Brown J, Mackay-Sim A. McGrath J, Feron F. Vitamin D3 and brain development. Neuroscience 2003;118:641-53.

37. Eyles DW, Berne TH, McGrath JJ. Vitamin D, effects on brain development, adult brain function and the links between low levels of vitamin D and neuropsychiatric disease. Front Neuroendocrinol 2013;34:47-64.

38. McGrath JJ, Burne TH, Féron F, Mackay-Sim A, Eyles DW. Developmental vitamin D deficiency and risk of schizophrenia: A 10year update. Schizophr Bull 2010;36:1073-8.

39. Theodoratou E, Tzoulaki I, Zgaga L, Ioannidis JP. Vitamin D and multiple health outcomes: Umbrella review of systematic reviews and meta-analyses of observational studies and randomised trials. BMJ 2014;348:2035.

40. Schwartz PJ. Season of birth in schizophrenia: A maternal-fetal chronobiological hypothesis. Med Hypothesis 2011;76:785-93.

41. McGrath JJ, Eyles DW, Pedersen CB, Anderson C, Ko P, Burne TH, et al. Neonatal vitamin D status and risk of schizophrenia: A population based case-control study. Arch Gen Psychiatry 2010;67:889-94.

42. Holick MF, Binkley NC, Bischoff-Ferrari HA, Gordon CM, Hanley DA, Heaney RP, et al. Evaluation, treatment and prevention of vitamin D deficiency: An endocrine society clinical practice guideline. J Clin Endocrinol Metab 2011;96:1911-30.

43. Valipour G, Saneei P, Esmaillzadeh A. Serum vitamin D levels in relation to schizophrenia: A systematic review and meta-analysis of observational studies. J Clin Endocrinol Metab 2014;99:3863-72.

44. Jan PA, Bostoen T, Theo GB. Low levels of vitamin D poorly responsive to daylight exposure in patients with therapy resistant schizophrenia. Nordic J Psychiatry 2015;10:262-6.

45. Graham KA, Keefe RS, Lieberman JA, Calikoglu AS, Lansing KM, Perkins DO, et al. Relationship of low vitamin D status with positive, negative and cognitive symptom domains in people with first-episode schizophrenia. Early Interv Psychiatry 2015;9:397-405.

46. Yao JK, Keshavan MS. Antioxidants, redox signaling, and pathophysiology in schizophrenia: An integrative view. Antioxid Redox Signal 2011;15:2011-35.

47. Mahadik, SP, Mukherjee S. Free radical pathology and antioxidant defense in schizophrenia: A review. Schizophr Res 1996;19:1-17.

48. Mukerjee S, Mahadik SP, Scheffer R, Correnti EE, Kelkar H. Impaired antioxidant defense at the onset of psychosis. Schizophr Res 1996;19:19-26.

49. Perez-Neri I, Ramirez-Bermudez J, Montes S, Rios C. Possible mechanisms of neurodegeneration in schizophrenia. Neurochem Res 2006;31:1279-94.

50. Do K, Bovet P, Cuenod M. Schizophrenia: Glutathione deficit as a new vulnerability factor for disconnectivity syndrome. Schweiz Arch Psyciatr 2004; 155:375-85

51. Do KQ, Trabesinger AH, Kirsten-Kruger M, Lauer CJ, Dydak U, Hell D, et al. Schizophrenia: Glutathione deficit in cerebrospinal fluid and prefrontal cortex in vivo. Eur J Neurosci 2000;12:3721-8.

52. Wood SJ, Berger GE, Wellard RM, Proffitt TM, McConchie M, Berk M, et al. Medial temporal lobe glutathione concentration in first episode psychosis: A 1HMRS investigation. Neurobiol Dis 2009;33:354-7.

53. Matsuzawa D, Obata T, Shirayama Y, Nonaka H, Kanazawa Y, Yoshitome E, et al. Negative correlation between brain glutathione level and negative symptoms in schizophrenia: A 3T 1H-MRS study. PLoS One 2008;3:e1944.

54. Gysin R, Kraftsik R, Sandell J, Bovet P, Chappuis C, Conus P, et al. Impaired glutathione synthesis in schizophrenia: Convergent genetic and functional evidence. Proc Natl Acad Sci USA 2007;104:16621-26.

55. Nicolaus M, Hildegard S, Volker A, Erfurth A. Severe tardive dyskinesia in affective disorders: Treatment with vitamin $\mathrm{E}$ and $\mathrm{C}$. Neuropsychobiology 2002;46:28-30.

56. Dorfman-Etrog P, Hermesh H, Prilipko L, Weizman A, Munitz H. The effect of vitamin $\mathrm{E}$ addition to acute neuroleptic treatment on the emergence of extrapyramidal side effects in schizophrenic patients: An open label study. Eur Neuro Psycho Pharmacol 1999;9:475-77.

57. Hoffer LJ. Vitamin Therapy in Schizophrenia. Isr J Psychiatry Relat Sci 2008;45:3-10

58. Brown HE, Roffman JL. Vitamin supplementation in the treatment of schizophrenia. CNS Drugs 2014;28:611-22.

59. Christopher W. Low B12 seen in aging, autism and schizophrenia. Live Sci 2016;10:1-2.

60. Shulman R. A survey of vitamin B12 deficiency in an elderly psychiatric population. Br J Psychiatry 1967;113:241-51.

61. Haidemenos A, Kontis D, Gazi A, Kallai E, Allin M, Lucia B. Plasma homocysteine, folate and B12 in chronic schizophrenia. Prog Neuro Psychopharmacol Biol Psychiatry 2007;31:1289-96.

62. Nishi A, Numata S, Tajima A, Kinoshita M, Kikuchi K, Shimodera S, et al. Meta-analyses of blood homocysteine level for gender and genetic association studies of the MTHFR C677T polymorphism in schizophrenia. Schizophr Bull 2014;40:1154-63.

63. Kale A, Naphade N, Sapkale S, Kamaraju M, Pillai A, Joshi S, et al. Reduced folic acid, vitamin B12 and docosahexaenoic acid and increased homocysteine and cortisol in never-medicated schizophrenia patients: Implications for altered one-carbon metabolism. Psychiatry Res 2010;175:47-53.

64. Roffman JL, Lamberti JS, Achtyes E, Macklin EA, Galendez GC, Raeke LH, et al. Randomized multicenter investigation of folate vitamins in schizophrenia plus vitamin B12 supplementation in schizophrenia. JAMA Psychiatry 2013;70:481-9.

65. Kemperman RF, Veurink $M$, van der Wal $T$, Knegtering $H$, Bruggeman R, Fokkema MR, et al. Low essential fatty acid and B-vitamin status in a subgroup of patients with schizophrenia and its response to dietary supplementation. Prostaglandins Leukot Essent Fatty Acids 2006;74:75-85

66. Muntjewerff JW, van der Put N, Eskes T, Ellenbroek B, Steegers E, Blom $\mathrm{H}$, et al. Homocysteine metabolism and B-vitamins in schizophrenic patients: Low plasma folate as a possible independent risk factor for schizophrenia. Psychiatry Res 2003;121:1-9.

67. Emily D. Folate and Negative Symptoms in Schizophrenia. Available from: https://www.psychologytoday.com. [Last accessed on 2013 Jul 16]

68. Abou-Saleh MT, Coppen A. The biology of folate in depression: Implications for nutritional hypotheses of the psychoses. J Psychiatr Res 1986;20:91-101.

69. Bottiglieri T, Laundy M, Crellin R, Toone BK, Carney MW, Reynolds EH. Homocysteine, folate, methylation, and monoamine 
metabolism in depression. J Neurol Neurosurg Psychiatry 2000;54:382-90

70. Godfrey PS, Toone BK, Carney MW, Flynn TG, Bottiglieri T, Laundy M, et al. Enhancement of recovery from psychiatric illness by methylfolate. Lancet 1990;336:392-5.

71. Roffman JL, Weiss AP, Purcell S, Caffalette CA, Freudenreich O, Henderson DC, et al. Contribution of methylenetetrahydrofolate reductase (MTHFR) polymorphisms to negative symptoms in schizophrenia. Biol Psychiatry 2008;63:42-8.

72. Goff DC, Bottiglieri T, Arning E, Shih V, Freudenreich O, Evins AE, et al. Folate, homocysteine, and negative symptoms in schizophrenia. Am J Psychiatry 2004;161:1705-8.

73. Vladimir L, Chanoch $M$, Alexander $K$, Cohen $H$, Matar $M$, Loewenthal U, et al. Vitamin B6 in the treatment of tardive dyskinesia: A double-blind, placebo-controlled, crossover study. Am J Psychiatry 2001;158:1511-4.

74. Winslow LC, Shapiro H. Physicians want education about complementary and alternative medicine to enhance communication with their patients. Arch Intern Med 2002;162:1176-81.

75. Lerner V, Miodownik C, Kaptsan A, Cohen H, Loewenthal U, Kotler M. Vitamin B6 as add-on treatment in chronic schizophrenic and schizoaffective patients: A double-blind, placebo-controlled study. J Clin Psychiatry 2002;63:54-8.

76. Levine J, Stahl Z, Sela BA, Ruderman V, Shumaico O, Babushkin I, et al. Homocysteine-reducing strategies improve symptoms in chronic schizophrenic patients with hyperhomocysteinemia. Biol Psychiatry 2006;60:265-9.

77. Spector RG, Lorenzo AV. Ascorbic acid homeostasis in the central nervous system. Am J Physiol 1973;225:757-63.

78. Saner A, Weiser H, Nornig D, De Prada M, Pletcher A. Cerebral monamine metabolism in guinea pigs with ascorbic acid deficiency. J Pharm Pharmacol 1975;27:896-902.

79. Deana R, Bharaj BS, Verjee ZM, Galzigna L. Changes relevant to catecholamine metabolism in liver and brain of ascorbic acid deficient guinea-pigs. Int J Vitam Nutr Res 1975;45:175-82.

80. Andersen JW, Shih JC. Necessity of ascorbic acid in the radioligand binding assay for $\left({ }^{3} \mathrm{H}\right)$ 5-hydroxytryptamine. Neuropharmacology 1986;25:869-75.

81. Wyatt RJ, Vaugham T, Galanter M, Karlan J, Green R. Behavioral changes of chronic schizophrenic patients given L-5-hydroxytryptophan. Science 1972;177:1124-6.

82. Pauling L. On the orthomolecular environment of the mind: Orthomolecular theory. Am J Psychiatry 1974;131:1251-7.

83. Vanderkamp H. A biochemical abnonnality in schizophrenia involving ascorbic acid. Int J Neuropsychiatry 1966;2:204-6.

84. Herjanic M, Moss-Herjanic BL. Ascorbic acid test in psychiatric patients. J Schizophr 1967;1:257-60.

85. Thomas TN, Zemp JW. Inhibition of dopamine sensitive adenylate cyclase from rat brain striatal homogenates by ascorbic acid. J Neurochem 1977;28:663-5.

86. Tolbert LC, Thomas TN, Middaugh LD, Zemp JW. Effect of ascorbic acid on neurochemical, behavioral, and physiological symptoms mediated by catecholamines. Lqe Sci 1979;25:2189-95.

87. Heikkila RE, Manzino L, Cabbat FS, Hanly JG. Ascorbic acid and the binding of DA agonists to neostriatal membrane preparations. Neuropharmacology 1983;22:135-7.

88. Dakhale GN, Khanzode SD, Khanzode SS, Saoji A. Supplementation of vitamin $\mathrm{C}$ with atypical antipsychotics reduces oxidative stress and improves the outcome of schizophrenia. J Psychopharmacol $2005 ; 182: 494-8$ 